\title{
Sífilis maligna en un paciente con infección por VIH. Presentación de un caso y revisión de la literatura
}

\author{
Marcelo Corti, Rubén Solari, Luis De Carolis, Olga Figueiras, Natalia Vittar y Esteban Maronna
}

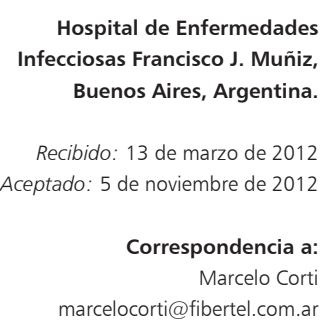

Hospital de Enfermedades . Muñiz, (n)

\section{Malignant syphilis in a patient infected by human immunodeficiency virus. Case report and literature review}

Malignant syphilis is a rare form of secondary syphilis strongly associated with human immunodeficiency virus infection (HIV). This clinical form of the disease is characterized by atypical cutaneous ulcerative and disseminated lesions and systemic compromise that can delay the final diagnosis. There are only few reports in the medical literature about malignant lues in HIV-infected patients. Malignant syphilis should be considered in the differential diagnosis in HIV-infected patients with fever and ulcerative skin lesions. Here we describe a man who developed clinical cutaneous and systemic manifestations pathologically confirmed as malignant syphilis and we performed a review of the literature.

Key words: Malignant syphilis, HIV, Treponema pallidum.

Palabras clave: Sífilis maligna, VIH, Treponema pallidum.

\section{Introducción}

L a sífilis maligna es una forma clínica grave de esta enfermedad que en la actualidad se observa en asociación con la infección por el virus de la inmunodeficiencia humana (VIH). Se caracteriza por manifestaciones clínicas inespecíficas y lesiones cutáneas extensas, polimorfas, destructivas y ulcerativas, algunas con características rupioides, que pueden comprometer la vida del paciente. Las lesiones papulosas, nodulares y ulcerativas pueden estar cubiertas por costras y evolucionan en forma lenta hacia la cicatrización ${ }^{1,2}$. La incidencia global de sífilis secundaria maligna es baja; Shulkin y cols. ${ }^{3}$ identificaron sólo 14 casos publicados en la literatura científica en idioma inglés entre los años 1900 y 1988. Sin embargo, a partir de la epidemia de VIH/ SIDA la incidencia se ha incrementado, sugiriendo que la infección por el retrovirus podría ser un factor de riesgo para desarrollar esta forma clínica ${ }^{4,5}$.

Se presenta un paciente con infección por VIH con un cuadro clínico de sífilis maligna, diagnóstico confirmado por los hallazgos histopatológicos de una biopsia cutánea y que respondió favorablemente al tratamiento con penicilina.

\section{Caso clínico}

Paciente varón, heterosexual, con diagnóstico de infección por VIH dos años antes, ocasión en que presentó una tuberculosis pulmonar. En ese momento, el VDRL era negativo y no refería antecedentes de otras infecciones de transmisión sexual. El paciente completó tratamiento antituberculoso con buena respuesta; al mes de iniciado el mismo, con una carga viral para VIH de 2.241 céls/ $\mathrm{ml}\left(\log _{10} 3,35\right)$ y un recuento de linfocitos T CD4 de 354 céls $/ \mathrm{ml}$, comenzó con tratamiento anti-retroviral con zidovudina, lamivudina y efavirenz que abandonó un mes después. Fue internado por presentar compromiso del estado general con fiebre intermitente, artralgias, mialgias y lesiones cutáneas diseminadas, pápulo-nodulares y algunas ulceradas, en el tronco, cara y extremidades y lesiones maculares palmo-plantares de tres semanas de evolución. Algunas lesiones se encontraban cubiertas de costras (Figuras 1, 2 y 3). El examen de la mucosa oral, genital y anal no evidenció lesiones; el examen oftalmológico y la evaluación neurológica fueron normales. Los estudios de laboratorio iniciales mostraron: VHS $87 \mathrm{~mm} /$ primera hora, recuento de leucocitos $8.400 / \mathrm{mm}^{3}$ (neutrófilos $59 \%$ y linfocitos 29\%), GOT 27 UI/1, GPT 25 UI/l, glicemia $114 \mathrm{mg} / \mathrm{dl}$, uremia $15 \mathrm{mg} / \mathrm{dl}$, creatininemia $0,70 \mathrm{mg} / \mathrm{dl}$, VDRL 1:512 y microhemaglutinación para Treponema pallidum (MHA-TP) reactiva. El recuento de linfocitos T CD4 era de 267 céls $/ \mathrm{mm}^{3}$ y la carga viral plasmática de 2.543 copias $/ \mathrm{ml}\left(\log _{10} 3.41\right)$. La escarificación de una de las lesiones cutáneas úlcero-costrosa mostró un infiltrado inflamatorio inespecífico, con tinciones de Gram, ZiehlNeelsen y Giemsa negativas. Con diagnóstico de sífilis secundaria maligna se le efectuó una punción lumbar obteniéndose LCR con presión normal, transparente, proteínas $41 \mathrm{mg} / \mathrm{dl}$; glucorraquia $55 \mathrm{mg} / \mathrm{dl}$ y 5 células mononucleares. Las tinciones con tinta china, Giemsa, Gram y Ziehl-Neelsen fueron negativas. El VDRL en el LCR resultó no reactivo. 


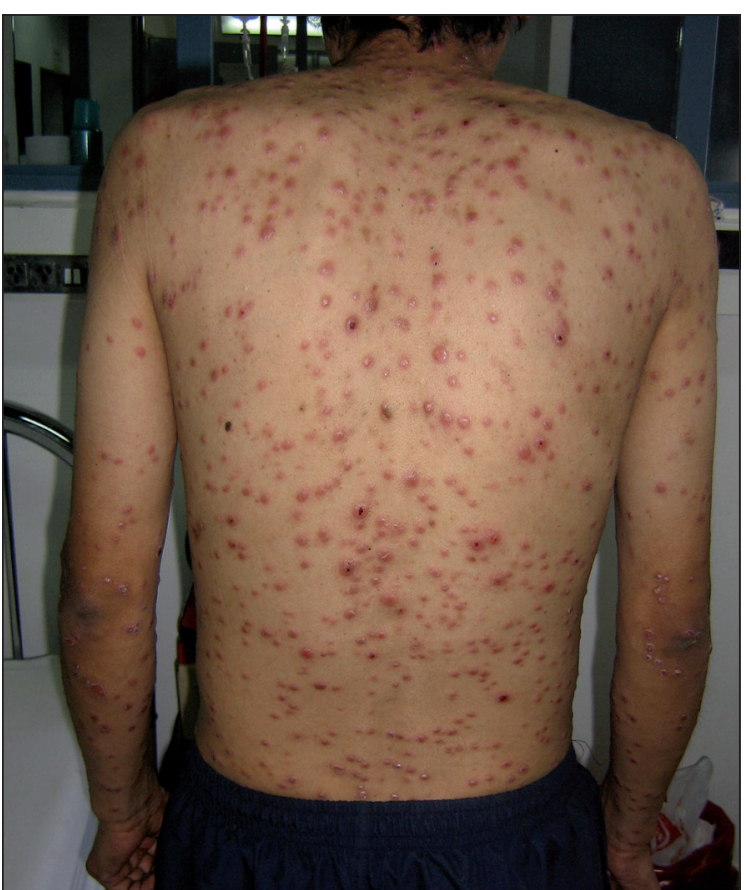

Figura 1. Lesiones papulosas y ulcero-costrosas, distribuidas de forma difusa en todo el dorso.

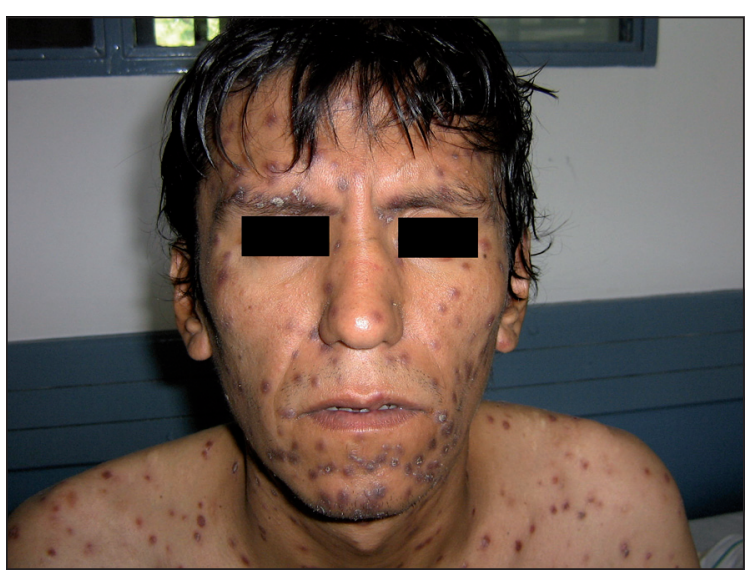

Figura 2. Lesiones pápulo-úlcero-costrosas en la cara.

Se realizó una biopsia cutánea de una de las lesiones nodulares de tronco. El estudio histopatológico con tinción de hematoxilina-eosina mostró una epidermis con paraqueratosis, acantosis irregular, intensa exocitosis linfocitaria y abundantes cuerpos coloides. En la dermis se observaron densos infiltrados inflamatorios de disposición subepitelial, perivascular y perianexial constituidos por linfocitos, histiocitos y algunas células plasmáticas. El diagnóstico histopatológico fue de una dermatitis de interfase con patrón liquenoide e infiltrados linfo-plasmocitarios perivasculares y perifoliculares. Los hallazgos morfológicos descritos fueron compatibles con

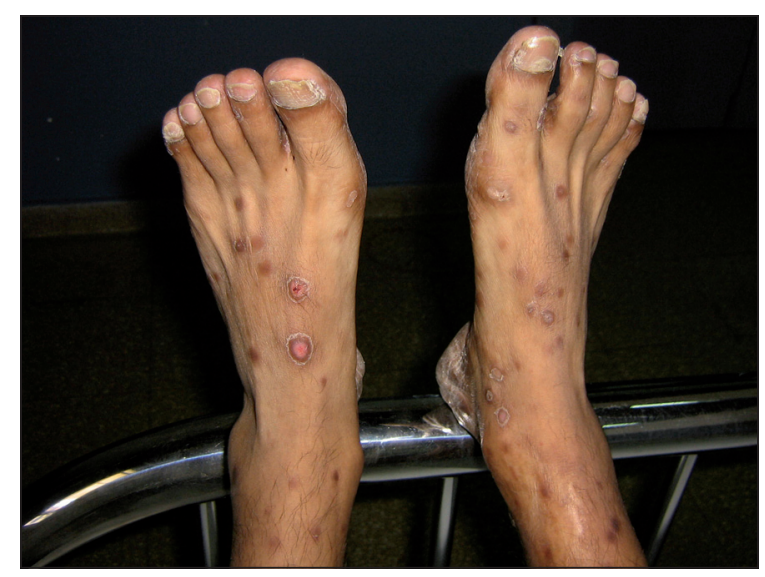

Figura 3. Compromiso de ambos pies por lesiones en diferentes estadios evolutivos.

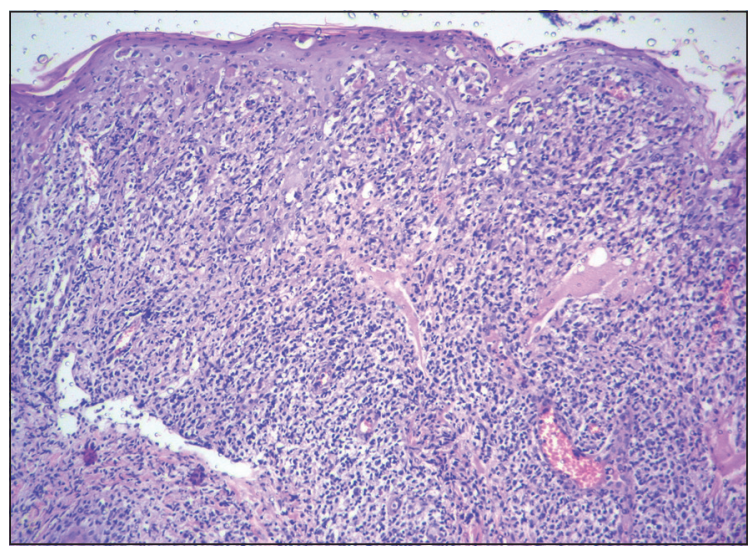

Figura 4. Histopatología, hematoxilina-eosina 100 aumentos: epidermis con hiperparaqueratosis, acantosis, exocitosis linfocitaria basal, abundantes cuerpos coloides y degeneración hidrópica basal. Dermis con denso infiltrado inflamatorio linfocitario en banda subepitelial.

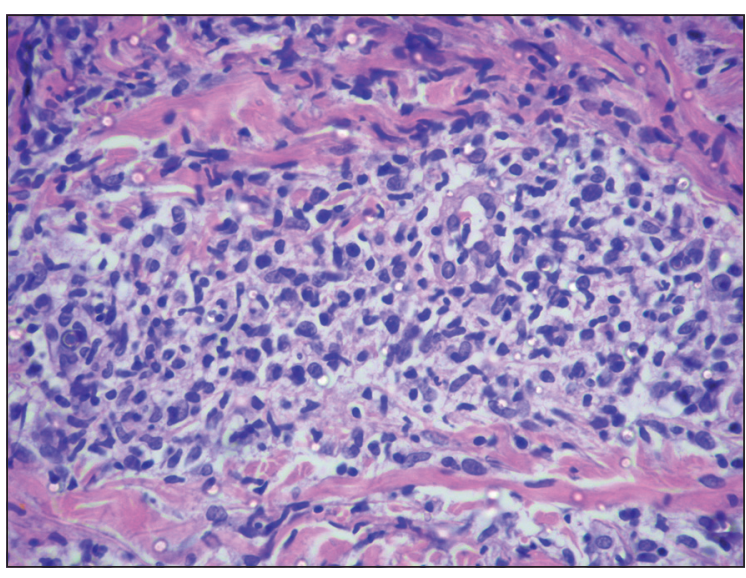

el diagnóstico de lúes secundaria. Las tinciones de PAS, Ziehl-Neelsen y Warthin Starry resultaron negativas para la identificación de microorganismos (Figuras 4 y 5).

Se indicó tratamiento con penicilina benzatina 2,4 millones UI por vía IM una vez por semana durante 4 semanas. Hubo resolución de las lesiones cutáneas
Figura 5. Histopatología, hematoxilina-eosina 400 aumentos: Se observan los infiltrados perivasculares en dermis profunda, constituidos por linfocitos, histiocitos epitelioides y células plasmáticas. 
Figura 6. Lesiones residuales pigmentadas en el tronco con posterioridad al tratamiento completo.

Figura 7. Máculas pigmentadas residuales en la cara a la finalización de la terapia.
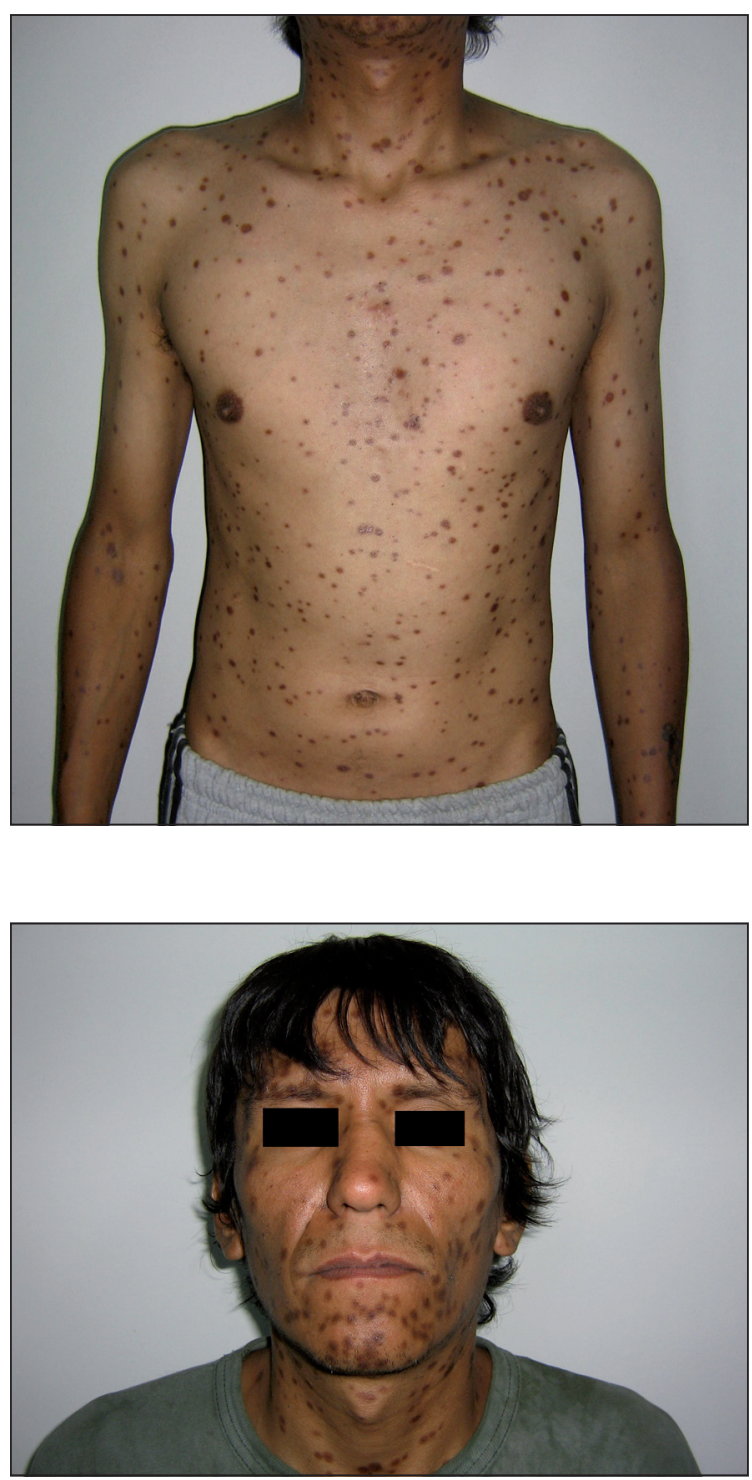

evolucionando a máculas hiperpigmentadas en el rostro, tronco y extremidades, de $5 \mathrm{~mm}$ de diámetro aproximadamente, como lesiones secuelares (Figuras 6 y 7). No se observaron eventos adversos secundarios al tratamiento indicado (reacción de Jarisch-Herxheimer). A los 6 meses, el VDRL había descendido su titulación en 4 veces, a 1:32, señalando una adecuada respuesta al tratamiento indicado.

\section{Discusión}

La primera descripción de la sífilis maligna fue publicada por Neisser y Hasslund en $1897^{6}$; se trata de una forma de sífilis secundaria, agresiva y con marcado compromiso del estado general. El primer caso en un paciente con infección por VIH se publicó en $1988^{3}$.
En un estudio retrospectivo, multicéntrico, alemán que incluyó 11.368 sujetos con infección por VIH, 151 $(1,3 \%)$ presentaron sífilis pero sólo 11 de ellos $(7,3 \%)$ desarrollaron la forma secundaria maligna ${ }^{7}$. La sífilis maligna es una forma clínica infrecuente de presentación de esta infección en pacientes con enfermedad por VIH/ SIDA $^{8}$. Predomina en hombres y se caracteriza por lesiones ulceradas, cubiertas de costras, que cubren casi toda la superficie cutánea, como pudimos observar en el paciente que describimos. Se acompañan de manifestaciones sistémicas como fiebre, artralgias, mialgias, decaimiento y cefalea y, a veces, compromiso de la mucosa bucal. Los pacientes con co-infección VIH/T. pallidum pueden desarrollar formas clínicas atípicas de la treponematosis, alteraciones en la respuesta serológica y una respuesta inadecuada a la terapia específica ${ }^{9,10}$. Romero-Jiménez y cols. ${ }^{6}$ en una búsqueda bibliográfica efectuada en la base de datos Medline de PubMed, recolectaron 21 casos de sífilis maligna en pacientes con infección por VIH publicados entre los años 1996 y 2000. En esta serie de casos, $62 \%$ de los pacientes eran varones, con una mediana de 34 años y con un recuento de linfocitos T CD4 >200 céls/ $\mathrm{mm}^{3}$ en $80 \%$ de los casos, como en el caso que se presenta. Todos los pacientes tenían lesiones cutáneas ulceradas, con centro necrótico y en diferente estadio evolutivo, a veces acompañadas de dolor y prurito. De todos los casos, $33 \%$ presentaron compromiso ocular y en $24 \%$ de los pacientes se comprobaron lesiones de la mucosa bucal. Nuestro paciente no tuvo manifestaciones oculares, del sistema nervioso ni lesiones oro-genitales. Las pruebas serológicas fueron positivas en todos los casos. La histopatología mostró la presencia de espiroquetas mediante la tinción de Warthin-Starry en sólo 12 de 21 pacientes (57\%). Por esta razón, el diagnóstico de sífilis maligna se confirma habitualmente por los hallazgos histopatológicos de la biopsia de las lesiones cutáneas, siendo infrecuente la identificación de espiroquetas ${ }^{11,12}$. Éstas pueden ponerse de manifiesto utilizando técnicas de inmunohistoquímica o las tinciones de Warthin-Starry o de Steiner ${ }^{13,14,15}$. La amplia serie presentada por Don y cols. ${ }^{3}$ incluyó a seis pacientes con infección por VIH con sífilis maligna en los que la tinción de Warthin-Starry no pudo demostrar la presencia de espiroquetas en las lesiones y lo propio ocurrió en la serie de Tucker y cols. ${ }^{16}$ en la que se utilizó la tinción de Steiner. La ausencia de espiroquetas en el infiltrado inflamatorio también se comprueba en los sujetos no infectados por VIH ${ }^{17}$. Hasta el año 2011 sólo se habían publicado seis casos de sífilis maligna en pacientes con infección por VIH confirmados por hallazgos histopatológicos ${ }^{12}$. En el paciente que describimos, si bien no se observaron espiroquetas con las tinciones especiales, la histopatología fue característica de sífilis con densos infiltrados linfo-plasmocitarios localizados en la dermis y rodeando anexos cutáneos y vasos. 
Además de los hallazgos histopatológicos, los criterios para el diagnóstico de sífilis maligna incluyen pruebas serológicas reactivas a títulos elevados, manifestaciones clínicas frecuentes de reacción de Jarisch-Herxheimer con el inicio del tratamiento y rápida resolución de las lesiones con la terapia adecuada ${ }^{18}$. En nuestro paciente pudimos comprobar dos de estos tres criterios de diagnóstico. No se observó reacción de Jarisch-Herxheimer.

El diagnóstico diferencial de los pacientes infectados por VIH con lesiones cutáneas extensas, en diferente estadio evolutivo y acompañadas de síntomas generales incluyen: histoplasmosis diseminada, tuberculosis miliar cutánea, herpes simplex y herpes zoster diseminados y las erupciones polimorfas por fármacos.

Penicilina es siempre el tratamiento de elección para estos pacientes y generalmente se asocia a buena respuesta clínica ${ }^{10}$. A pesar de la gravedad de esta forma de presentación, el pronóstico en general es bueno, con remisión de las lesiones en un plazo variable de tiempo y desaparición más precoz de los síntomas generales. Como pudimos apreciar en nuestro caso, suelen quedar lesiones secuelares como máculas pigmentadas.

En conclusión, la sífilis maligna debe incluirse en el diagnóstico diferencial de los pacientes con infección por VIH con fiebre y lesiones ulcerativas cutáneas profundas y diseminadas, algunas cubiertas de costras y acompañadas de manifestaciones de compromiso sistémico.

\section{Resumen}

La sífilis maligna es una forma rara de presentación de lúes secundaria asociada a la infección por el virus de la inmunodeficiencia humana (VIH). Se caracteriza por lesiones cutáneas atípicas, ulceradas, costrosas y diseminadas, asociadas con síntomas generales inespecíficos que pueden retrasar el diagnóstico correcto. Existen sólo escasas publicaciones en la literatura médica acerca de sífilis maligna en pacientes con infección por VIH. La lúes maligna debe incluirse en el diagnóstico diferencial de los pacientes con VIH que consultan por fiebre y lesiones úlcero-costrosas diseminadas. Se describe el caso de un paciente con infección por VIH que desarrolló una sífilis maligna con confirmación diagnóstica a partir de los hallazgos histopatológicos y se realiza una revisión de la literatura científica sobre el tema.

\section{Referencias bibliográficas}

1.- Rajan J, Prasad P V, Chockalingam K, Kaviarasan P K. Malignant syphilis with human immunodeficiency virus infection. Indian Dermatol Online J 2011; 2: 19-22.

2.- Corti M, Villafañe M F, Palmieri O, Negroni R. Rupioid histoplasmosis: first case reported in an AIDS patient in Argentina. Rev Inst Med Trop Sao Paulo 2010; 52: 279-80.

3.- Shulkin D, Tripoli L, Abell E. Lues maligna in a patient with human immunodeficiency virus infection. Am J Med 1988; 85: 425-7.

4.- Don P C, Rubinstein R, Christie S. Malignant syphilis (lues maligna) and concurrent infection with HIV. Int J Dermatol 1995; 34: 403-7.

5.- Sands M, Markus A. Lues maligna, or ulceronodular syphilis, in a man infected with human immunodeficiency virus: case report and review. Clin Infect Dis 1995; 20: 387-90.

6.- Romero-Jiménez M J, Suárez Lozano I, Fajardo Picó J M, Barón Franco B. Sífilis maligna en paciente infectado por el virus de la inmunodeficiencia humana (VIH): descripción de un caso y revisión de la literatura. An Med
Interna 2003; 20: 373-6.

7.- Schofer H, Imhof M, Thoma-Greber E, Brockmeyer NH, Hartmann M, Gerken G, et al. Active syphilis in HIV infection: a multicentre retrospective survey. The German AIDS Study Group (GASG). Genitourin Med 1996; 72: 176-81.

8.- Dibbern D A Jr, Ray S C. Recrudescence of treated neurosyphilis in a patient with human immunodeficiency virus. Mayo Clin Proc 1999; 74: 53-6.

9.- Hutchinson C M, Hook E W 3rd, Shepherd M, Verley J, Rompalo A M. Altered clinical presentation of early syphilis in patients with human immunodeficiency virus infection. Ann Intern Med 1994; 121: 94-100.

10.- Tosca A, Stavropoulos P G, Hatziolou E, Arvanitis A, Stavrianeas N, Hatzivassiliou M, et al. Malignant syphilis in HIV-infected patients. Int J Dermatol 1990; 29: 575-8.

11.- Kumar B, Muralidhar S. Malignant syphilis: a review. AIDS Patient Care. STDS 1998; 12: 921-5.

12.- Yanagisawa N, Ando M, Imamura A, Akagi K, Horiguchi S, Suganuma A, et al. Pathologically confirmed malignant syphilis in an HIV-infected patient. Intern Med 2011; 50: 2423-6.

13.- D’Amico R, Zalusky R. A case of lues maligna in a patient with acquired immunodeficiency syndrome (AIDS). Scan J Infect Dis 2005; 37 : 697-700.

14.- Ficarra G, Zaragoza A M, Stendardi L, Parri F, Cockerell C J. Early oral presentation of lues maligna in a patient with HIV infection. A case report.Oral Surg Oral Med Oral Pathol 1993; 75: 728-32.

15.- De Rie M A, Mekkes J R, Cohen E B, Hulsebosch H J. Syphilis maligna: a HIV related problem?. Br J Dermatol 1991; 125: 390-1.

16.- Tucker J D, Shah S, Jarell A D, Tsai K Y, Zembowicz A, Kroshinsky D. Lues maligna in early HIV infection: case report and review of the literature. Sex Transm Dis 2009; 36: 512-4.

17.- Bahmer F A, Anton-Lamprecht L. Ultrastructural features of malignant syphilis and demonstration of Treponema pallidum. Int $\mathrm{J}$ Dermatol 1983; 22: 165-70.

18.- Fisher D A, Chang L W, Tufanelli D L. Lues maligna. Presentation of a case and review of the literature. Arch Dermatol 1969; 99: 70-3. 